\title{
Digital Transformation: A Reflection from HRM Perspective
}

\author{
Zhou $\mathrm{Q}^{1}$, Wang $\mathrm{J}^{1}$, Fu $\mathrm{F}^{1 *}$, Liu $\mathrm{B}^{2}$ and Guan $\mathrm{J}^{3}$ \\ ${ }^{1}$ School of Economics and Management, Beijing University of Chemical Technology, China \\ ${ }^{2}$ Law School, Ocean University of China, China \\ ${ }^{3}$ Library, Qingdao Film Academy, China
}

*Corresponding author: Feiqiang $\mathrm{Fu}$, School of Economics and Management, Beijing

University of Chemical Technology, China, Email: fufeiqiang@163.com

\section{Perspective}

Volume 6 Issue 1

Received Date: February 24, 2022

Published Date: March 02, 2022

DOI: $10.23880 / \mathrm{mhrij}-16000167$

\section{Abstract}

Affected by the worldwide digital technology revolution and industrial transformation, based on the new stage of highquality development characterized by digitalization, domestic and foreign scholars continue to pay more attention to digital transformation. Although some progress has been made, research in the field of enterprise digital transformation mostly focuses on the impacts of digital transformation on macro-management issues, while research in micro-management areas such as organizational behavior and human resources is still in its early stage. Given this status quo, this article focuses on enterprise human resource management (HRM) issue related to digital transformation and proposes path map regarding talent management, performance and compensation management, labour relation, recruiting, training and development programs. This article hopes to advance and promote current understanding on human resource management issues after transformation.

Keywords: Digital Transformation; Human Resource Management; Path Map

\section{Perspective}

Team building is pivotal to enterprise digital transformation [1]. The key to the digital transformation of products, technologies, enterprises, industries and even the economy as a whole lies in the major adjustment of the labour supply side. The degree of digital development of enterprises is actually the final manifestation of the digitalization process of the whole society. If the professional skills and competencies of employees are not constantly upgraded and optimized in line with the digital transformation of the macro economy, especially if the employees directly involved in specific businesses and operations do not meet the technical requirements of the digital transformation of their positions, it will be difficult to achieve breakthroughs in products and technologies, or to implement large-scale applications of those digital technologies that are already mature. This impact, rooted in the low digital literacy of employees, will continue to be transmitted and affect the digital transformation of enterprises and the digitalization process of countries on a more profound level.

The digital transformation of enterprises has brought new opportunities and challenges to the construction of enterprise talent teams [2]. We need to be fully aware of the changes in work caused by digitization in our daily management on the basis of traditional human resource management activities. For example, enterprise managers should consider the changes in work brought about by digital transformation, and ponder what changes in the mental state of employees have been caused by these new changes? What are the emotional factors behind these changes? Does the highly digital, automated machinery and equipment really improve the productivity of individual employees, 


\section{Mental Health \& Human Resilience International Journal}

or does it make employees aware of potential threats and risks of unemployment? What are the characteristics and barriers to interaction among employees in a humancomputer interaction environment? How to circumvent the skills shortage of employees when learning and using new equipment, and improve employees' professional skills and digital literacy rapidly through effective training methods? These are the new issues of human resource management faced by enterprises in the process of digital transformation, which need to summarize management experience and rules with the deepening of the digitalization process.

Therefore, improving the digital literacy of employees from a wider audience and a deeper level, and realizing the leading action from the perspective of team building will provide inexhaustible driving force for the digital transformation. Focusing on the main functions of enterprise human resource management, the leading action to realize the digital transformation from the perspective of team building can be divided into five modules. By reshaping and adjusting the content and structure of the following five functional modules, the digital professionalism of employees at all levels of the enterprise will be enhanced and the corresponding knowledge and skills will be improved in depth.

First, human resource management in the context of digital transformation. The digital transformation of the production methods and organizational forms of enterprises will bring about huge changes in the working environment. The automation, instrumentation and digitization of machinery and equipment have led to profound changes in operation methods, significantly altering the content and form of work and posing new challenges to the skills and knowledge of employees [3]. Thus, building a talent system that matches the strategic objectives to help the digital transformation of the enterprise first requires the enterprise and its managers to transform the concept and means of human resource management based on the individual psychological and cultural characteristics of employees. This means that managers should not only grasp employees' attitudes toward new technologies and equipment, but also clarify their behavioural patterns and psychological states when learning and accepting new production methods, so as to effectively optimize the work style, work efficiency and job satisfaction in the new work environment [4], and cooperate with an appropriate performance evaluation system and compensation incentive system to cope with new problems arising in the new environment.

Second, performance management and comprehensive compensation design based on digital transformation strategy. Performance management and compensation management are at the core of enterprise human resource management. In order to respond to the overall strategic adjustment of the digital transformation of enterprises, and to stimulate and promote the digital literacy of the workforce from a deep level, enterprises need to combine cutting-edge performance management tools and analysis the core issues of performance management and compensation incentives in the process of digital transformation in depth [5]. Based on the degree of digital transformation in different departments and levels of the enterprise, update and reconstruct the concepts and tools of performance management and compensation management for important categories of employees, establish a differentiated compensation incentive mechanism, open up the closed loop of performance management, and realize the double-wheel drive of employee pressure and motivation [6].

Third, labour regulations and labour relations management in the context of digital transformation. Usually, the nature of ownership, organizational form, scale and employment form of enterprises has different impacts on industrial relations. At present, the digital transformation of enterprises will lead to potential job changes and personnel retention issues, shaping new characteristics of industrial relations and these changes involve different levels of norms, morality, and laws. Meanwhile, due to the new background of marketization, industrialization, urbanization, informatization and internationalization, employees' awareness of their rights is getting stronger, their interests are increasingly demanding, and the legal cost of enterprises is getting higher, which is the new normal of labour relations nowadays. In the process of team building in the context of digital transformation, enterprises can build a harmonious labour relations management by standardizing all aspects of selection, training, employment, retention and redundancy to lay a solid foundation for enterprises to carry out digital transformation.

Fourth, recruitment innovation to serve the digital strategy of enterprises. One of the main ways to solve the human resource problems in the digital transformation of enterprises is to carry out recruitment innovation, that is, to attract and select talents with both digital skills and business knowledge from the source to match the new positions and new needs generated by the strategic transformation of enterprises. There is not only a shortage of this type of complex talent with certain experience, but also a fierce competition in the market, which is often attracted by many job demands [7]. Thus, in the process of digital transformation, enterprises should take strategic objectives as the guide, build talent standards, carve out and identify key positions and clarify recruitment needs through methods such as indicator identification systems and rating standards. And fully combine the assistance of new recruitment platforms and tools in the mobile Internet environment to meet the development needs of enterprises precisely, quickly and 


\section{Mental Health \& Human Resilience International Journal}

efficiently, build a mature talent team and reserve sufficient human resources for digital transformation [8].

Fifth, talent strategy and training development in the context of digital transformation of enterprises. Another major way to solve the human resource problem of digital transformation is to develop a new talent strategy of training and developing existing human resources to continuously adapt to the new overall corporate strategic development needs. On the one hand, enterprises should conduct inventory and identification of key talents in the process of digital transformation, design appropriate talent assessment tools and systems according to the standards and competency requirements of different levels, such as grassroots, middle and senior levels, and identify and establish a talent pool with hierarchical classification by combining the actual distribution of existing personnel quality. On the other hand, it integrates the existing hierarchical talent pool with the requirements of emerging positions and new job qualifications, designs targeted training programs for various types of talents, effectively improves the quality of talents, and comprehensively using internal and external resources to help key talents grow rapidly to meet the needs of strategic transformation of the organization. Further, the establishment of a new talent strategy and training development system should be matched with corresponding compensation incentives, performance assessment standards and management mechanisms to form a closed loop of management, so as to effectively provide the underlying guarantee for the implementation of team building.

On the whole, talent team building is the key link in the realization of strategic restructuring in the process of enterprise digital transformation, providing fundamental guarantee for the implementation and application of various digital tools such as equipment, technology and products. On the basis of the talent team reconstruction combined with HR management functional modules, at the macro level, enterprises should also focus on the reconstruction of organizational structure [3] and talent ecology, establish and improve a new, efficient, digital strategy-oriented HR management model covering all aspects of human resource management in a broad sense; fully combine with industry characteristics, apply strategic performance management tools such as balanced scorecard and OKR, integrate value chain customer-oriented, efficiency-enhancing, fullcycle, full-process management thinking, combined with cloud platform, big data, Internet of Things and other key technologies and tools in the digitalization process, to deeply promote innovation management and organizational management of the entire enterprise [9], providing new micro-vitality for the digital strategic reconstruction of macro enterprises (Figure 1).

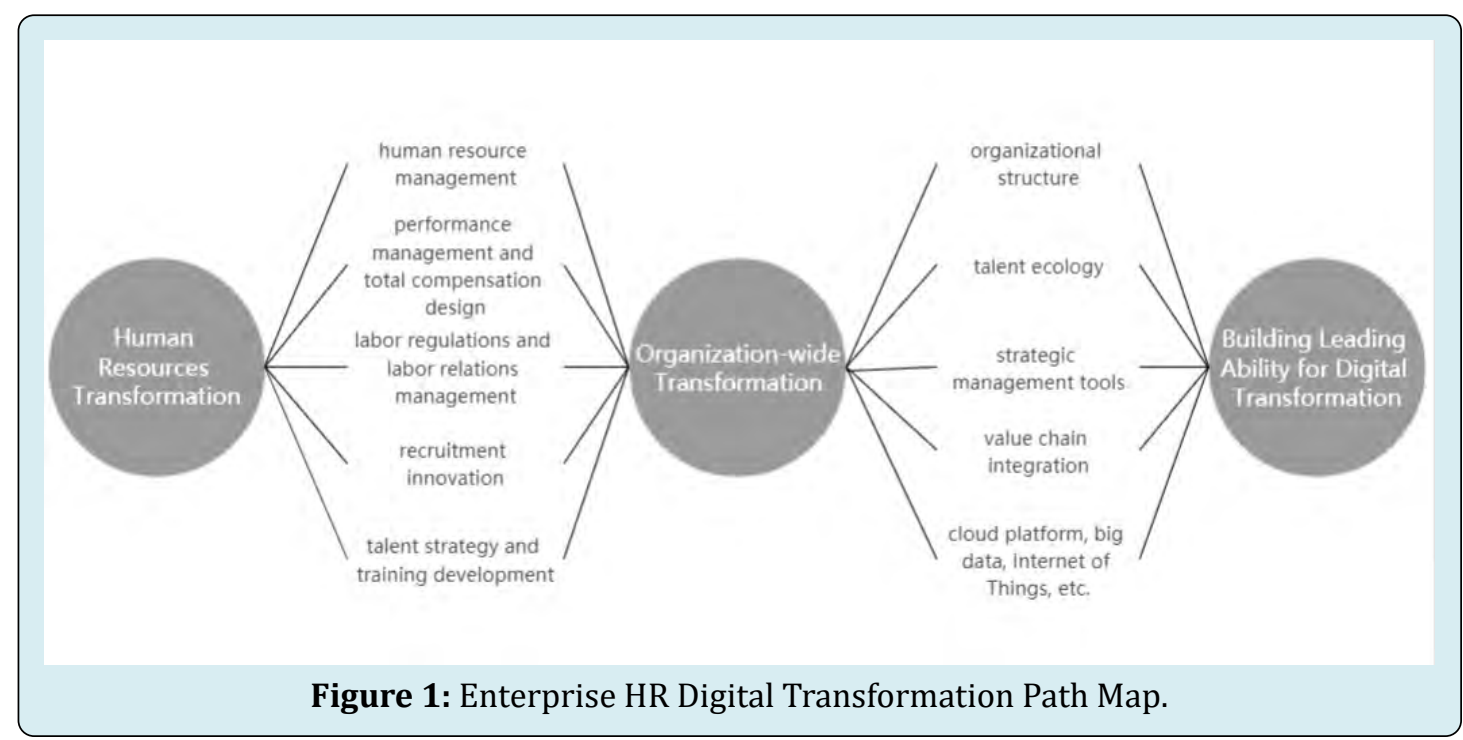

\section{Funding}

This study was supported by Beijing Social Science Foundation (No. 21GLC049).

\section{References}

1. Eller R, Alford P, Kallmünzer A, Peters M (2020)
Antecedents, consequences, and challenges of small and medium-sized enterprise digitalization. Journal of Business Research 112: 119-127.

2. Cascio WF, Montealegre R (2016) How technology is changing work and organizations. Annual Review of Organizational Psychology and Organizational Behavior 3: 349-375. 


\section{Mental Health \& Human Resilience International Journal}

3. Vial G (2021) Understanding digital transformation: A review and a research agenda. Journal of Strategic Information Systems 28(2): 118-144.

4. Johnson RD, Gueutal H, Falbe CM (2009) Technology, trainees, metacognitive activity and e-learning effectiveness. Journal of Managerial Psychology 24(6): 545-566.

5. Stone DL, Deadrick DL, Lukaszewski KM, Johnson $R$ (2015) The influence of technology on the future of human resource management. Human Resource Management Review 25(2): 216-231.

6. Hassard J, Morris J (2021) The extensification of managerial work in the digital age: Middle managers, spatio-temporal boundaries and control. Human
Relations, pp: 1-32.

7. Verhoef $\mathrm{PC}$, Broekhuizen $\mathrm{T}$, Bart $\mathrm{Y}$, Bhattacharya A, Dong JQ et al. (2021) Digital transformation: A multidisciplinary reflection and research agenda. Journal of Business Research 122: 889-901.

8. Schneider S, Kokshagina O (2021) Digital transformation What we have learned (thus far) and what is next. Creativity and Innovation Management 30(2): 384-411.

9. Appio FP, Frattini F, Petruzzelli AM, Neirotti P (2021) Digital transformation and innovation management: A synthesis of existing research and an agenda for future studies. Journal of Product Innovation Management 38(1): 4-20. 